\title{
Tribocorrosion Mechanisms of Ti6Al4V in Artificial Saliva by Zero-Resistance Ammetry (ZRA) Technique
}

\author{
M. P. Licausi · A. Igual Muñoz • V. Amigó Borrás • \\ N. Espallargas
}

Received: 7 November 2014/Revised: 15 January 2015/Accepted: 19 January 2015/Published online: 4 February 2015

(c) Springer International Publishing AG 2015

\begin{abstract}
Degradation mechanisms of biomedical alloys involve two different phenomena, corrosion and wear, which simultaneously act and may cause the failure of implants and prosthesis. In this work, tribocorrosion of Ti6Al4V biomedical alloy in artificial saliva is studied at open circuit potential (OCP) by a new electrochemical technique that allows measuring the galvanic potential and current between the wear track (anode) and the passive material (cathode) through zero-resistance ammetry. The experimental set-up was conceived for physically separating the depassivated area from the passive material, thus allowing to quantify the mechanically activated corrosion at OCP. Two different counterparts, $\mathrm{SiC}$ and $\mathrm{Al}_{2} \mathrm{O}_{3}$, were used against the Ti6Al4V alloy in order to analyse the influence of the initial contact pressure on the tribocorrosion mechanisms. A galvanic model based on the cathodic reaction kinetics can describe the current and the potential evolution with time during sliding. It has been observed that at the highest initial contact pressures, wear follows the Archard law, while at lower contact pressures, third body appeared and wear can not be described by the Archard law. Quantification of the evolution of the
\end{abstract}

M. P. Licausi · A. I. Muñoz (ه)

Institute for Industrial, Radiophysical and Environmental Safety, Universitat Politècnica de València, UPV, Camino de Vera s.n., 46022 Valencia, Spain

e-mail: anigmu@iqn.upv.es

M. P. Licausi · V. A. Borrás

Institute of Materials Technology, Universitat Politècnica de

València, UPV, Camino de Vera s.n., 46022 Valencia, Spain

N. Espallargas

Tribology Lab., Department of Engineering Design and

Materials, Faculty of Engineering Science and Technology,

NTNU, 7491 Trondheim, Norway depassivated wear track with time was obtained and the deviation from the Archard predictions was analysed.

Keywords Biotribocorrosion - Corrosion - Ti6Al4V . Zero-resistance ammetry · Galvanic model

\section{Introduction}

Titanium and its alloys are widely used in the biomedical field due to their excellent properties: low density, high hardness, good corrosion resistance, inactivity with the biological environment, low elastic modulus and high capacity to attach to tissue and bone, thus making titanium a good choice as a biomaterial [1-3]. Commercially pure titanium ( $\alpha$ alloy) and the Ti6Al4V alloy $(\alpha+\beta$ alloy) have been the most employed alloys for dental implants during years, although they exhibit prolonged use limitations such as high elastic modulus compared to the bone, and low wear resistance $[4,5]$. Ti6Al4V was also found to be toxic due to the release of aluminium and vanadium ions $[6,7]$. All these adverse effects are related to the degradation mechanisms of the alloy under operating conditions, which are typically the combined effect of corrosion and wear. The corrosion behaviour of titanium alloys depends on an oxide film formation mainly composed of $\mathrm{TiO}_{2}$, which spontaneously covers the titanium surface in the presence of oxygen [8]. The chemical properties of the oxide layer play an important role in the biocompatibility of titanium implants and the surrounding tissues, but typically its chemical and electrochemical stability is known to be very good. On the contrary, the mechanically activated corrosion and the wear resistance of titanium alloys are very dependent on the mechanical $[7,9,10]$ and electrochemical conditions [7, 11], which also may change 
during sliding. Several authors $[7,9,12]$ observed potential and current transitions during different tribocorrosion tests carried out on titanium alloys. Those transitions were explained through changes in wear mechanisms. Komotori et al. [9] observed a transition from abrasive to adhesive wear when increasing the scratching rate of the tests; Moore et al. [7] observed a change in the depassivation/ repassivation rate caused by the decrease in contact pressure during wear and Runa et al. [12] explained the decrease in current during rubbing by the formation of a tribolayer. In all cases, there is not a clear understanding of the mechanisms that cause the transitions in the electrochemical signals. The development of new triboelectrochemical techniques is, therefore, needed for identifying critical parameters determining the different tribocorrosion mechanisms during wear and for predicting and quantifying the involved phenomena.

Tribocorrosion testing of passive metals has been a topic of interest since late 1970s for investigating the synergistic effects of corrosion on wear and viceversa [13]. Measuring the combined action of wear and corrosion is not an easy task and it requires the use of electrochemical techniques and tribometers. Typically, the electrochemical techniques used in tribocorrosion (summarized in Ref. [14]) have been the measurement of the open circuit potential (OCP) while rubbing, potentiodynamic techniques (i.e. the variation of potential with time during rubbing and the measurement of current) and potentiostatic techniques (i.e. the application of a constant electrode potential while rubbing and the measurement of current). These techniques have allowed the proposal of tribocorrosion mechanisms and models [13, 14]. The use of electrochemical techniques is necessary for advancing in tribocorrosion modelling and more accurate techniques focusing onto the passivation/depassivation kinetics of passive metals are necessary in the field.

Recently, a new electrochemical technique for measuring currents during OCP has been proposed [15]. This technique physically separates the anode and the cathode in a tribocorrosion system and uses a zero-resistance ammeter (ZRA) for measuring the cathodic potential and the anodic current. The ZRA-tribocorrosion technique has allowed the experimental validation of the galvanic coupling model for tribocorrosion first proposed by Vieira et al. [16] for Aluminium alloys and later expanded by Papageorgiou and Mischler [17] for Co- and Ti-based alloys and by Papageorgiou et al. [18] for Ni-based alloys. The galvanic coupling model for tribocorrosion simulates the evolution of OCP with time during a tribocorrosion experiment assuming an anodic current density $\left(i_{\mathrm{a}}\right)$ that is used as a fitting parameter. The ZRA-tribocorrosion technique experimentally determines $i_{\mathrm{a}}$ and therefore allows to accurately model the potential evolution with time and eliminates the need of using fitting parameters. So far this experimental technique has been only validated with a $\mathrm{Fe}$ based alloy where a good correlation between the model using a fitting parameter and the experimental results was obtained at high loads. However, when the load was decreased, a constant decay in current and an increase in potential with time were obtained causing a deviation from the model using a fitting parameter [15]. This can be explained by the fact that the mechanical aspects of the system played a role, i.e. a deviation from the Archard wear law happened, which led to a different triboelectrochemical response. Therefore, the ZRA technique can be used as a tool for explaining tribocorrosion mechanisms.

The aim of this work has been to extend the validation of the ZRA technique to other passive alloys and to use it as a tool for investigating tribocorrosion mechanisms at OCP, which typically corresponds to a more realistic condition of operation. Specifically, in this work, a biomedical Ti6A14V cast alloy immersed in artificial saliva (AS) has been chosen for this purpose, and it has been tested at different applied contact pressures to study the influence of the mechanical conditions on the potential and current responses.

\section{Experimental Procedure}

\subsection{Materials and Electrolyte}

The metal alloy used in this work was an as-cast Titanium alloy, Ti6Al4V Grade 5, with a chemical composition in wt\% N: 0.02; C: 0.03; H: 0.011; Fe: 0.22; O: 0.16; Al: 6.12; $\mathrm{V}: 3.93$. The sample was cut from a plate of commercially available Ti6Al4V, thus specimens $25 \times 25 \times 5 \mathrm{~mm}^{3}$ were obtained.

Specimens were wet-ground with $220-4,000$ grit silicon carbide paper and further polished with diamond suspension to a mirror-like finishing $(\mathrm{Ra}=0.05 \pm 0.01 \mu \mathrm{m})$. After polishing, the samples were rinsed in water and dried using a stream of compressed air.

The electrolyte used in this work was a modified $\mathrm{Fu}$ sayama Meyer AS. The chemical composition of this solution, which closely resembles natural saliva, is $0.4 \mathrm{~g}$ $\mathrm{NaCl}, 0.4 \mathrm{~g} \mathrm{KCl}, 0.6 \mathrm{~g} \mathrm{CaCl}_{2}, 0.58 \mathrm{~g} \mathrm{Na}_{2} \mathrm{HPO}_{4} 12 \mathrm{H}_{2} \mathrm{O}$, $1 \mathrm{~g}$ urea and distilled water $1 \mathrm{~L}$. The electrolyte was used in the tests at $37^{\circ} \mathrm{C}$.

\subsection{Electrochemical Tests}

Cathodic polarization tests were carried out in order to determine the cathodic kinetics of the alloy in the studied electrolyte. For these experiments, an electrochemical cell with a three-electrode configuration (an $\mathrm{Ag} / \mathrm{AgCl} / \mathrm{KClsat}$ as reference electrode, a $\mathrm{Pt}$ wire as counter electrode and the 
titanium sample as working electrode) and a potentiostat (Autolab PGSTAT $302 \mathrm{~N}$ ) were used. All potentials in this paper are given with respect to the $\mathrm{Ag} / \mathrm{AgCl} / \mathrm{KClsat}$ electrode $(0.205 \mathrm{~V}$ vs SHE). The working electrode of each sample was fixed at the bottom of the electrochemical cell, exposing an area of $0.78 \mathrm{~cm}^{2}$ to the solution. After the stabilization of the OCP, the cathodic polarization curves were recorded dynamically at a scan rate of $5 \mathrm{mV} / \mathrm{min}$ from the OCP towards $-1 \mathrm{~V}$ with respect to the OCP. Each measurement was carried out at least two times in order to check the repeatability of the experiments.

\subsection{Tribocorrosion Tests by Zero-Resistance Ammetry}

The tribocorrosion tests of this study were carried out coupling a ZRA to a ball-on-flat reciprocating tribometer (TriboCorr, Resmat Corporation, Canada) in a customized electrochemical cell with a physically separated cathode and anode of the same material described in detail elsewhere [15]. The ZRA allows one to measure the galvanic current between the passive (cathode) and depassivated (anode) areas of the sample during tribocorrosion testing at OCP. To do that, one of the samples (the anode) was covered by an organic coating thus after the first stroke the coating was removed and only the depassivated area (anode) was exposed to the electrolyte. The second sample remained passive (cathode) and physically separated from the previous one (Fig. 1). The cathode area was $2.8 \mathrm{~cm}^{2}$ for all experiments.

This experimental set-up enables on the one hand to measure the galvanic potential $E_{\mathrm{c}}$, which is equivalent to the OCP measured in a standard tribocorrosion set-up [15] with no separation of cathode-anode and on the other hand to record the anodic current during the tribocorrosion experiment at OCP. The same reference electrode as the one used in the electrochemical tests was used for the tribocorrosion tests. Potential and current values were acquired simultaneously to the rubbing process.

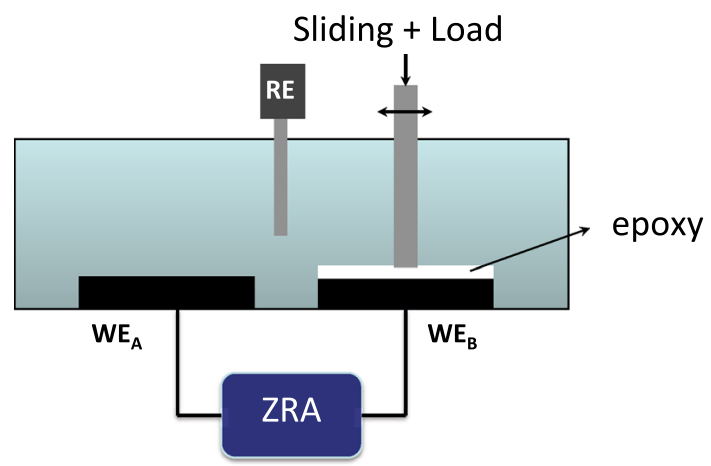

Fig. 1 Scheme of the electrochemical measurements carried out through a zero-resistance ammeter (ZRA) where $\mathrm{WE}_{\mathrm{A}}$ is the cathode (unrubbed sample), $\mathrm{WE}_{\mathrm{B}}$ is the anode (rubbed sample) and $\mathrm{RE}$ is the reference electrode (a)

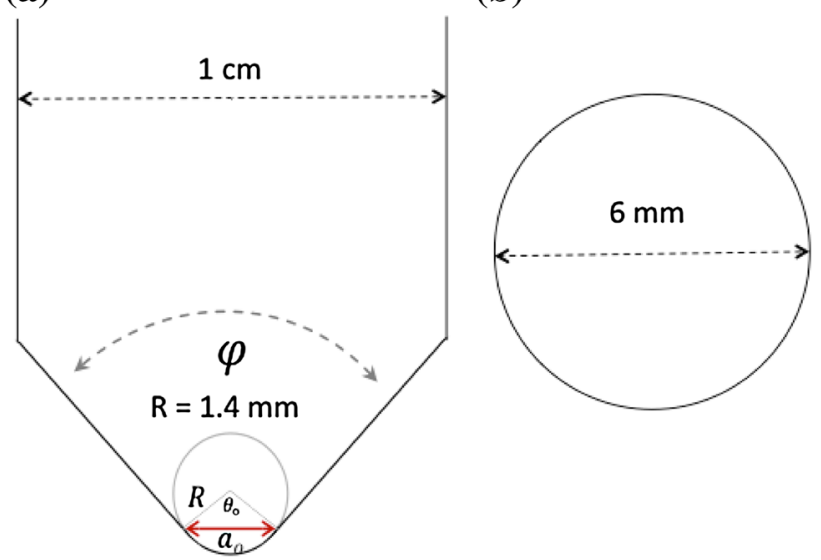

Fig. 2 Scheme of the $\mathbf{a} \mathrm{SiC}$ pin and $\mathbf{b}$ alumina ball geometry used as counterpart for the tribocorrosion tests

The sliding was established by rubbing two different counter bodies, an alumina ball of $6 \mathrm{~mm}$ in diameter and a $\mathrm{SiC}$ pin, against the anode sample. The $\mathrm{SiC}$ pin was a cylinder of $1 \mathrm{~cm}$ diameter, which was ground axisymmetrically to a conical tip of $90^{\circ}$ angle. The very end of the tip was microscopically rounded to a spherical finish with a diameter of $2.8 \mathrm{~mm}$ (blunt conical pin). Figure 2 shows a sketch of the pin. In all cases, the frequency of the sliding pin was $1 \mathrm{~Hz}$. The applied normal load used for the alumina ball was $3 \mathrm{~N}$, which corresponded to an initial average contact pressure of $540 \mathrm{MPa}$. For the $\mathrm{SiC}$ pin, two normal loads of 2 and $10 \mathrm{~N}$ were used, which corresponded to initial average contact pressures of 830 and $1,410 \mathrm{MPa}$, respectively. The yield strength of the alloy is $880 \mathrm{MPa}$. The potential, current and the frictional force were continuously monitored. Each measurement was carried out two times with new counterparts to check the repeatability of the experiments.

The volume loss was quantified by means of confocal microscopy (IFM Alicona, Austria) at the end of the tests. Cross-sectional profiles were taken across the wear track for each sample. The width and depth of the wear track was measured from the wear track cross section taken at three positions along the wear track and measured twice at each position. By multiplying these by the length of the track, the volume loss was then calculated.

The wear track topography was analysed by scanning electron microscopy (SEM) JEOL6300.

\section{Results}

\subsection{Cathodic Behaviour}

Figure 3 shows the cathodic polarization curves of the cast Ti6Al4V alloy in AS. The current density linearly increases 


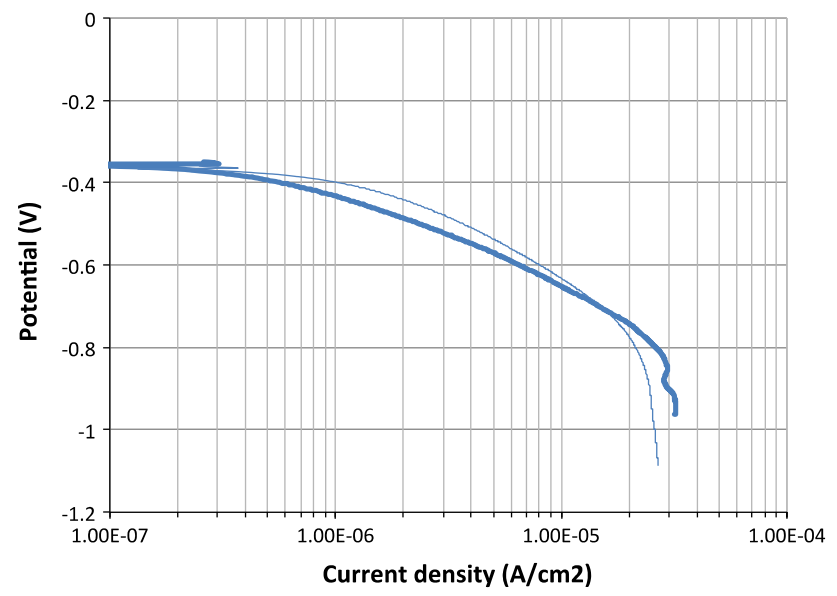

Fig. 3 Cathodic curves of the Ti6Al4V alloy in artificial saliva at $37^{\circ} \mathrm{C}$. Two repetitions are shown in the figure for checking repeatability

(negative sign) with the applied potential from around -0.4 to $-0.8 \mathrm{~V}$; thus, the cathodic Tafel equation can be used for describing the current evolution with the applied potential:

$\eta=a_{\mathrm{c}}-b_{\mathrm{c}} \log (i)$,

where $\eta$ is the overpotential $\left(E-E_{\text {corr }}\right), a_{\mathrm{c}}$ and $b_{\mathrm{c}}$ are the Tafel coefficients and $i$ is the current density. By carrying out the linear regression the Tafel coefficients, $a_{\mathrm{c}}=-2.2$ and $b_{\mathrm{c}}=0.23$, were obtained.

\subsection{Tribocorrosion at $\mathrm{OCP}$}

Typical potential and current evolution with time in a tribocorrosion test carried out using the ZRA technique as described in Sect. 2.3 are shown in Fig. 4. The graphs show the electrochemical response for the Ti6Al4V at different contact pressures, achieved by applying different loads and changing the geometry and material of the counterpart. In all cases, at the onset of rubbing, the potential decays due to the galvanic coupling established between the anode and the cathode while the current abruptly increases due to the flow of electrons from the anode to the cathode.

The magnitude of the potential decay is mainly dependent on the counterpart geometry and thus on the initial contact pressure. There is a clear jump in potential decay between $540 \mathrm{MPa}$ and the other two contact pressures, which indeed follows the yield strength of the material (880 MPa). In the case of the current evolution with time, surprisingly the highest current values are found for the smallest initial contact pressure. For the largest initial contact pressures, the current evolution with time is nearly the same analogously to the potential evolution with time.
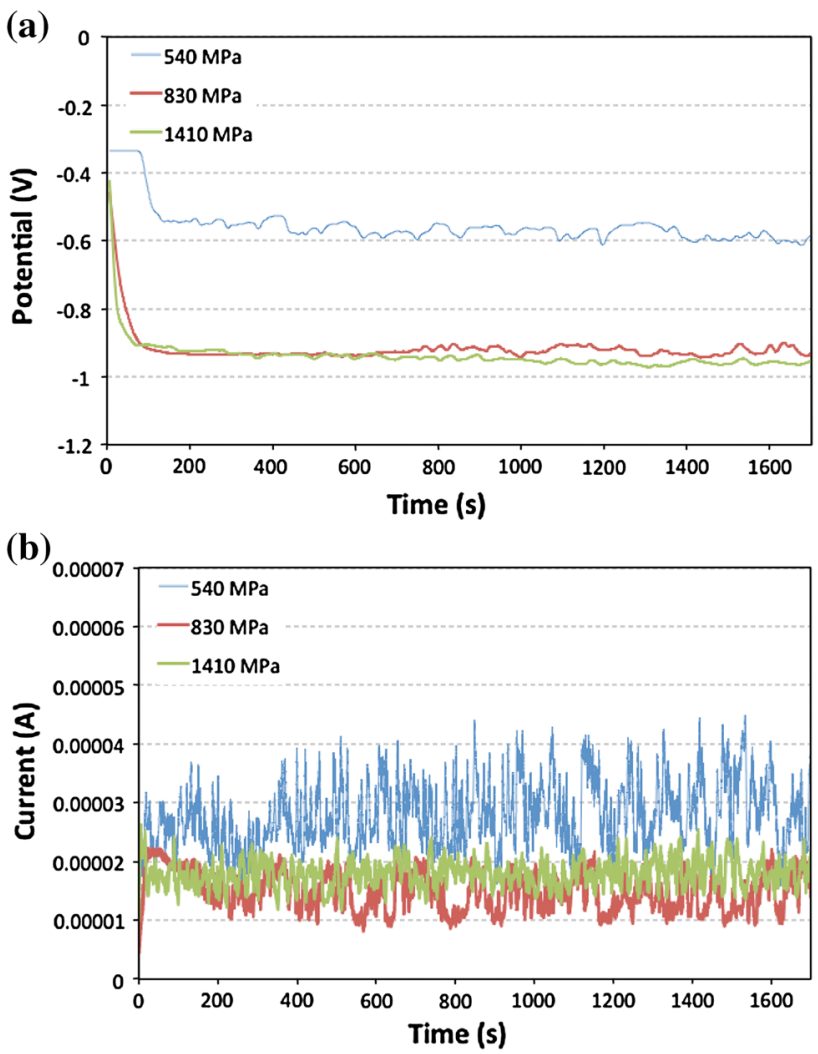

Fig. 4 a Potential and b current evolution with time for the Ti6Al4V alloy in artificial saliva at $37{ }^{\circ} \mathrm{C}$. Only one test result is shown in the graphs for clarity; however, the repetition tests were successful

\subsection{Wear}

The total volume loss $\left(V_{\text {tot }}\right)$ was measured by non-contact profilometry (Alicona, IFM), and the chemical $\left(V_{\text {chem }}\right)$ and mechanical $\left(V_{\text {mech }}\right)$ contributions were quantified using the current obtained during rubbing after the tribocorrosion tests (Fig. 4b) and applying Faraday's law (Eq. 1) and the mechanistic approach for tribocorrosion (Eq. 2) [13]. The results are summarized in Table 1 . The chemical volume corresponds to the amount of material loss caused by wear accelerated corrosion and the mechanical volume is the difference between $V_{\text {tot }}$ and $V_{\text {chem }}$.

$V_{\text {chem }}=\frac{I t M}{n F \rho}$

$V_{\text {total }}=V_{\text {mech }}+V_{\text {chem }}$,

where $V_{\text {chem }}$ is the volume loss due to the metal oxidation during time $t, V_{\text {total }}$ is the total material loss in the wear track, $V_{\text {mech }}$ is the mechanical volume loss, $I$ is the anodic current measured during rubbing, $F$ is the Faraday's constant (approximately 96,500 C/mol), $n$ is the oxidation valence of the metal, $M$ is the atomic mass of the metal and $\rho$ is the density of the metal. 
Table 1 Volume loss values (total, chemical and mechanical) after tribocorrosion tests at OCP using the ZRA set-up

\begin{tabular}{llcccc}
\hline Pressure $(\mathrm{MPa})$ & Counterpart & $V_{\text {tot }}\left(\times 10^{-3}\right) \mathrm{mm}^{3}$ & $V_{\text {chem }}\left(\times 10^{-3}\right) \mathrm{mm}^{3}$ & $V_{\text {mech }}\left(\times 10^{-3}\right) \mathrm{mm}^{3}$ & Average friction \\
\hline 540 & $\mathrm{Al}_{2} \mathrm{O}_{3}$ & $24 \pm 7$ & $1.42 \pm 0.08$ & $23.3 \pm 7$ & $0.46 \pm 0.05$ \\
840 & $\mathrm{SiC}$ & $90 \pm 10$ & $0.67 \pm 0.05$ & $88.6 \pm 7$ & $0.34 \pm 0.01$ \\
1,410 & $\mathrm{SiC}$ & $130 \pm 7$ & $0.84 \pm 0.08$ & $129 \pm 7$ & $0.53 \pm 0.05$ \\
\hline
\end{tabular}

The average friction during rubbing is also shown in the table

The wear topography of the Ti6Al4V alloy and the alumina counterpart after tribocorrosion testing in AS is shown in Figs. 5 and 6, respectively. For the tests performed against $\mathrm{SiC}$ pin (largest initial contact pressures), the surface appears smooth and plastically deformed. When the counterpart material changes to alumina ball (lowest initial contact pressure), wear debris is observed on the wear track surface. Material transfer and wear of the counterpart are also observed.

\section{Discussion}

\subsection{Galvanic Coupling Model}

\subsubsection{Using $i_{a}$ as Fitting Parameter}

Vieira et al. developed a galvanic coupling model for tribocorrosion to interpreting and quantifying wear at OCP of aluminium alloys [16]. An electrochemical approach for
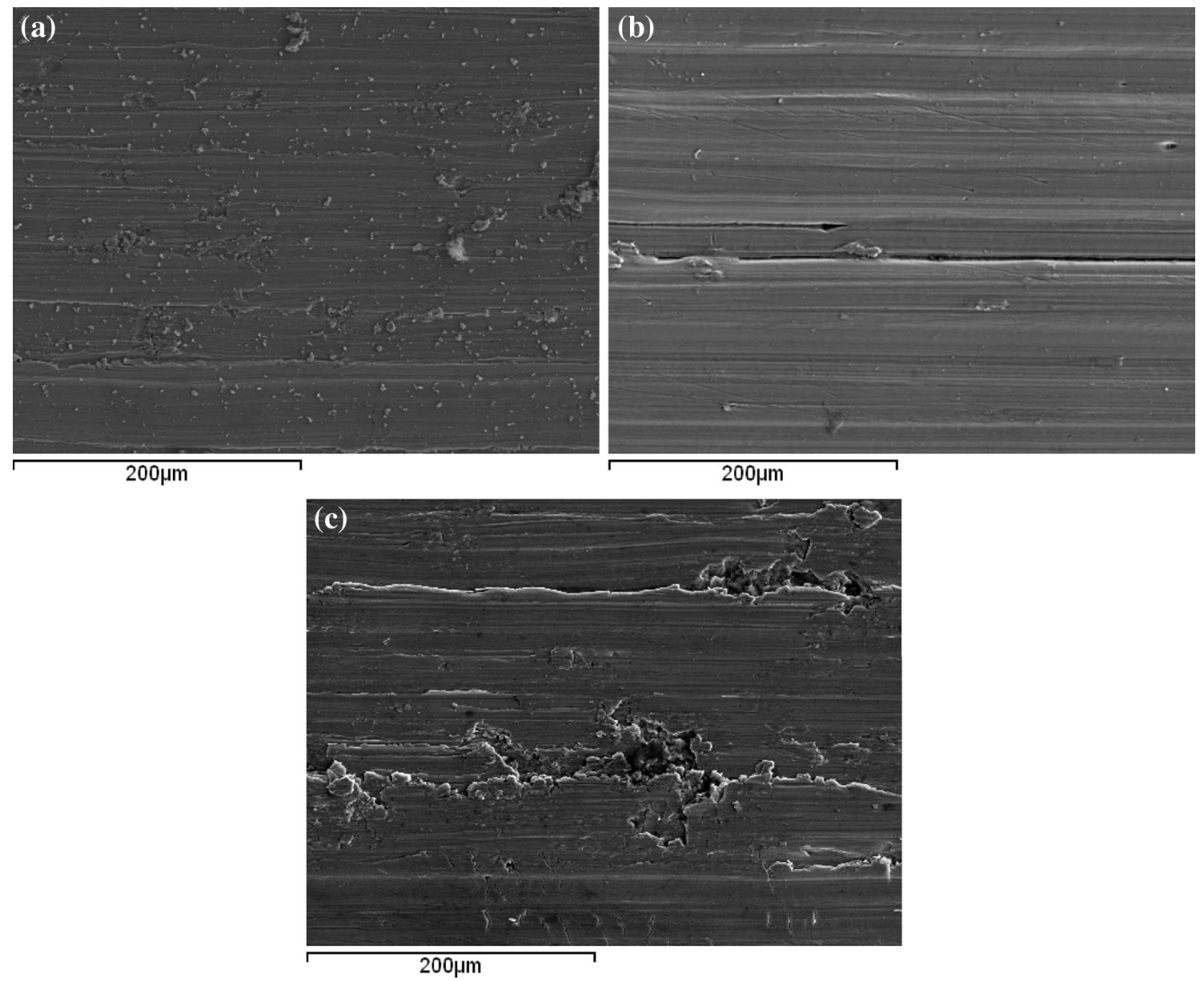

Fig. 5 SEM images of the center of the wear tracks after tribocorrosion testing in artificial saliva at OCP: a against alumina ball at $3 \mathrm{~N}$ normal load (540 MPa), b against $\mathrm{SiC}$ pin at $2 \mathrm{~N}$ normal load
(830 MPa) and $\mathbf{c}$ against $\mathrm{SiC}$ pin at $10 \mathrm{~N}$ normal load (1,410 MPa). The roughness of the wear tracks was $1 \mu \mathrm{m}$ for $\mathbf{a}$ and $\mathbf{b} 1.5 \mu \mathrm{m}$ for $\mathbf{c}$ 


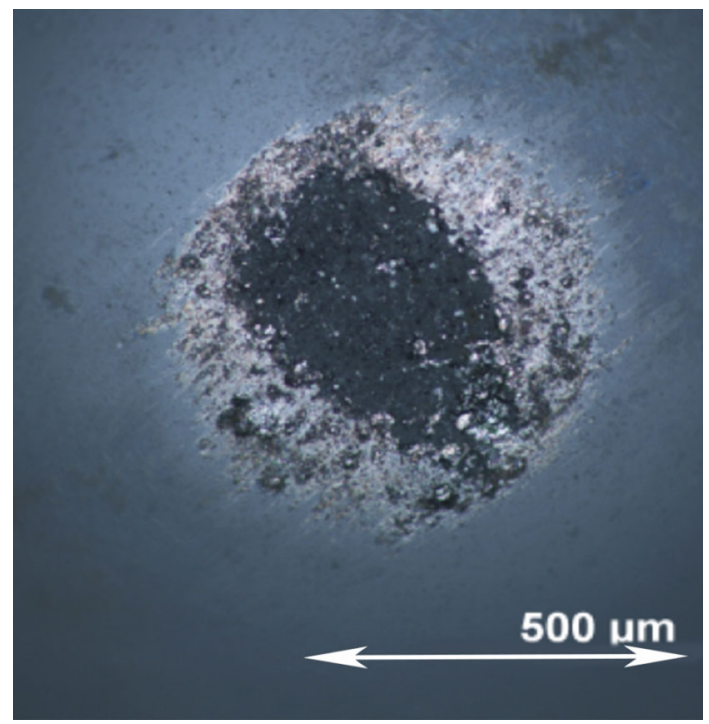

Fig. 6 Optical image of the alumina counterpart after tribocorrosion testing in artificial saliva at $3 \mathrm{~N}$ normal load

representing the cathodic potential as a function of kinetic parameters (Tafel coefficients and corrosion potential) and anode to cathode area ratio (ratio between the depassivated area and passive area) was proposed according to the following equation:

$E_{\mathrm{c}}=E_{\mathrm{corr}}+a_{\mathrm{c}}-b_{\mathrm{c}} \log i_{\mathrm{a}}-b_{\mathrm{c}} \log \frac{A_{\mathrm{a}}}{A_{\mathrm{c}}}$,

where $E_{\mathrm{c}}$ is the cathodic potential outside the wear track (the potential measured during tribocorrosion at OCP), $a_{\mathrm{c}}$ and $b_{\mathrm{c}}$ are constants calculated from Tafel equations, $i_{\mathrm{a}}$ is the anodic current density produced during the depassivation process inside the wear track, and $A_{\mathrm{a}}$ and $A_{\mathrm{c}}$ are the surface areas of the anode and the cathode, respectively.

The model is based on a simple galvanic coupling model used in corrosion, but adapted to tribocorrosion situations. The model requires not only kinetic parameters (which can be obtained from independent electrochemical tests such as cathodic potentiodynamic curves shown in Fig. 3) and the area ratios (which can be measured geometrically at the end of the test), but it also requires the anodic current $\left(i_{\mathrm{a}}\right)$, which was proposed as a fitting parameter. This fitting parameter should be constant for an experiment at a constant potential and during OCP testing it is expected to change as potential changes [17].

Figure 7 shows the experimental evolution of the galvanic potential with time for the Ti6Al4V alloy sliding against $\mathrm{SiC}$ and $\mathrm{Al}_{2} \mathrm{O}_{3}$ at the different initial contact pressures along with the mathematical simulation of the model (Eq. 3) using two different values for the fitting parameter $\left(i_{\mathrm{a}}=5\right.$ and $\left.0.5 \mathrm{~mA} / \mathrm{cm}^{2}\right)$. The $i_{\mathrm{a}}$ value of $5 \mathrm{~mA} /$ $\mathrm{cm}^{2}$ was previously used by Papageorgiou and Mischler when studying the tribocorrosion behaviour at $\mathrm{OCP}$ of pure
Titanium in $\mathrm{NaCl}$ [17]. In this work, a similar fitting parameter could be expected since for different passive metals, i.e. $\mathrm{Al}$, stainless steel and pure $\mathrm{Ti}$ values varying between 5 and $10 \mathrm{~mA} / \mathrm{cm}^{2}$ have been reported [16, 17]. When using $5 \mathrm{~mA} / \mathrm{cm}^{2}$ as fitting parameter, the modelled evolution of potential with time (red curve) is lower than the experimental values (blue curve) in all tribocorrosion tests. However, when changing the fitting parameter to one
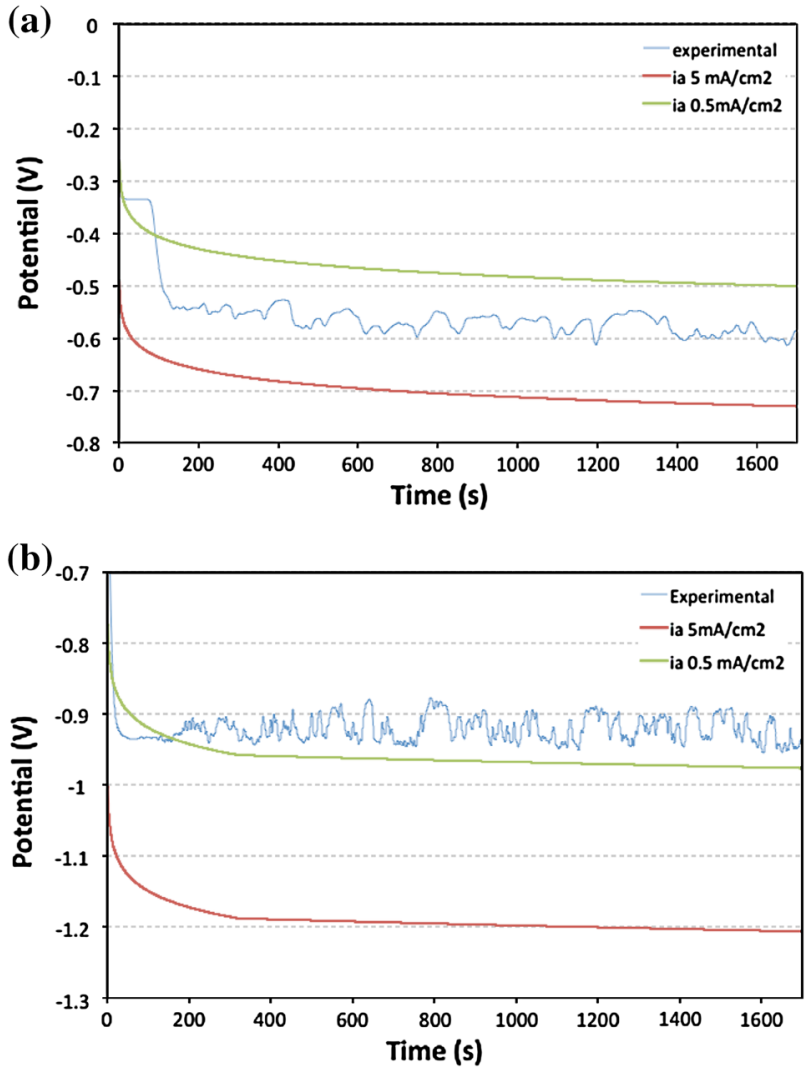

(c)

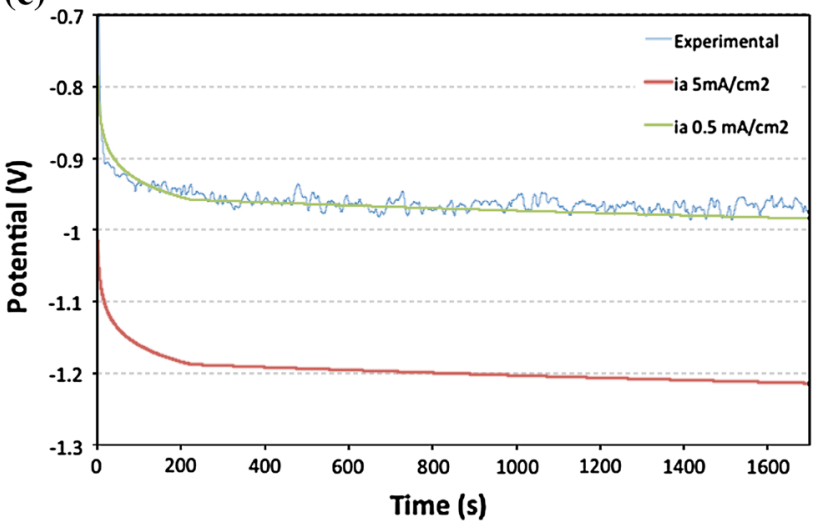

Fig. 7 Experimental potential evolution with time for the Ti6Al4 V against a $\mathrm{Al}_{2} \mathrm{O}_{3} 540 \mathrm{MPa}, \mathbf{b} \mathrm{SiC}$ pin 843 and $\mathbf{c} 1,410 \mathrm{MPa}$ measured by ZRA in artificial saliva at $37^{\circ} \mathrm{C}$. The model OCP (mathematical simulation) is superimposed in all figures according to equation $\mathrm{x}$ using $i_{\mathrm{a}}$ as fitting parameter 
order of magnitude lower, $0.5 \mathrm{~mA} / \mathrm{cm}^{2}$, the model perfectly fits for the largest initial contact pressure $(1,410 \mathrm{MPa})$, deviates slightly at $830 \mathrm{MPa}$ and predicts a more positive potential at $540 \mathrm{MPa}$.

Clearly, using a fitting parameter for modelling, the potential evolution is not a very accurate method for the experimental results obtained in this work. Indeed, Vieira et al. [16] already anticipated that the quantification approach taken when using a fitting parameter neglects relevant effects such as the increase of the wear track area induced by the surface roughening or debris particles formation, the deviation from the Archard wear behaviour in the initial run-in and non homogeneous potential distribution on the sample surface.

\subsubsection{Using Experimental Current Density (ZRA)}

For overcoming the limitations of using a fitting parameter for the galvanic coupling model, the experimental technique using a ZRA was proposed recently [15]. The ZRA technique allows measuring experimentally the galvanic potential and the anodic current $\left(i_{\mathrm{a}}\right)$ during rubbing by physically separating the wear track (anode) from the passive area (cathode) as shown in Fig. 1. Equations 3 and 4 have been applied using the measured anodic current $I_{\mathrm{a}}$ $\left(I_{\mathrm{a}}=i_{\mathrm{a}} A_{\mathrm{a}}\right)$ and the potential evolution during rubbing at OCP, respectively. The results of the experimental and the simulated values using ZRA are shown in Fig. 8, which shows the accuracy of the ZRA technique for modelling the potential and current evolution during sliding.

$\log i_{\mathrm{a}}=\frac{E_{\text {corr }}-E_{\mathrm{c}}+a_{\mathrm{c}}-b_{\mathrm{c}} \log \left(\frac{A_{\mathrm{a}}}{A_{\mathrm{c}}}\right)}{b_{\mathrm{c}}}$.

Measuring experimentally the potential and current evolution with time at OCP and applying the galvanic model, the ZRA technique can be used for determining the evolution with time of the relationship between the depassivated area (anode) with the wear track area predicted by Archard wear law. Assuming that the anodic current density $\left(i_{\mathrm{a}}\right)$ in Eq. 3 equals the anodic current measured during rubbing at OCP divided the Archard wear area $\left(A_{\mathrm{wt}}\right)$, the relationship between the real depassivated area $\left(A_{\mathrm{a}}\right)$ and the Archard prediction $\left(A_{\mathrm{wt}}\right)$ can be determined using the following equation:

$E_{\mathrm{c}}=E_{\text {corr }}+a_{\mathrm{c}}-b_{\mathrm{c}} \log \frac{I_{\mathrm{a}}}{A_{\mathrm{wt}}}-b_{\mathrm{c}} \log \frac{A_{\mathrm{a}}}{A_{\mathrm{c}}}$.

The wear track area $\left(A_{\mathrm{wt}}\right)$ can be determined considering the Archard wear law and the linear relationship between wear volume $\left(V_{\text {tot }}\right)$ and rubbing time $(t), V(t)=C_{\mathrm{w}} t$, where $C_{\mathrm{w}}$ is a constant that can be calculated by dividing the wear track volume measured at the end of the tests
(Table 1) by the duration of rubbing. Depending on the geometry of the counterpart, the $A_{\mathrm{wt}}$ and the theoretical area of contact as predicted by Hertz ( $\left.A_{\text {contact }}\right)$ can then be represented as a function of time [15, 17]. Figure 9 shows the evolution of the theoretical $\left(A_{\mathrm{wt}}\right)$ and experimental depassivated area $\left(A_{\mathrm{a}}\right)$ as a function of rubbing time. In the same graph, the Hertzian area of contact $\left(A_{\text {contact }}\right)$ has been also plotted for the different initial contact pressures. It is worth noticing that there is more than one order of magnitude difference between the Hertzian area of contact and the depassivated area of contact.

A good correlation between the wear track area and the depassivated area at the highest initial contact pressures was obtained (Fig. 9b, c). This correlation corresponds well with a clear plastic deformation of the wear tracks (Fig. $5 \mathrm{~b}, \mathrm{c}$ ). In both cases, the area rapidly increases at the beginning of the test and after around $200 \mathrm{~s}$, the slope abruptly changes. This change in slope is purely geometrical and it corresponds with the indenter reaching the conical part as already discussed in a previous work [15]. At $830 \mathrm{MPa}$ initial contact pressure, $A_{\mathrm{a}}$ is slightly lower than $A_{\mathrm{wt}}$, which means that not all wear track area is depassivated. Indeed, the relation $A_{\mathrm{a}} / A_{\mathrm{wt}}$ in this case is below $80 \%$ after the first $200 \mathrm{~s}$, while for the initial contact pressure of $1,410 \mathrm{MPa}$, it reaches $100 \%$. Assuming that depassivation occurs by plastic deformation of asperities, this is in good agreement with the SEM images that show less plastic deformation and small and isolated wear particles at $830 \mathrm{MPa}$, thus smaller $A_{\mathrm{a}}$ with respect to $A_{\mathrm{wt}}$.

Figure 9a shows the experimental results when the Ti6Al4V slides against an $\mathrm{Al}_{2} \mathrm{O}_{3}$ ball at an initial contact pressure of $540 \mathrm{MPa}$, which is well below the yield strength of the alloy thus no plastic behaviour is expected. In this case, $A_{\mathrm{a}}$ cannot be predicted by the Archard law as clearly shown in Fig. 9a, where $A_{\mathrm{wt}}$ is smaller than $A_{\mathrm{a}}$; therefore, the current is generated not only by the depassivation of the wear track but also by other wear mechanisms. Indeed, when observing the wear track after rubbing, a large amount of wear debris is present (Fig. 5a).

\subsection{Wear Mechanisms}

The ZRA-tribocorrosion technique allowed measuring both potential and current during rubbing at OCP. For the three tribocorrosion test conditions in this work, the highest current during rubbing was surprisingly obtained for the lowest initial contact pressure (540 $\mathrm{MPa}$, using an alumina ball as counterpart). The image of the alumina counterpart (Fig. 6) shows that together with material transfer some particles or grains of alumina could have been pulled out from the ball, analogously to what was reported by Dearnley et al. [19]. This may cause an increase in the chemical dissolution of the titanium surface when sliding 

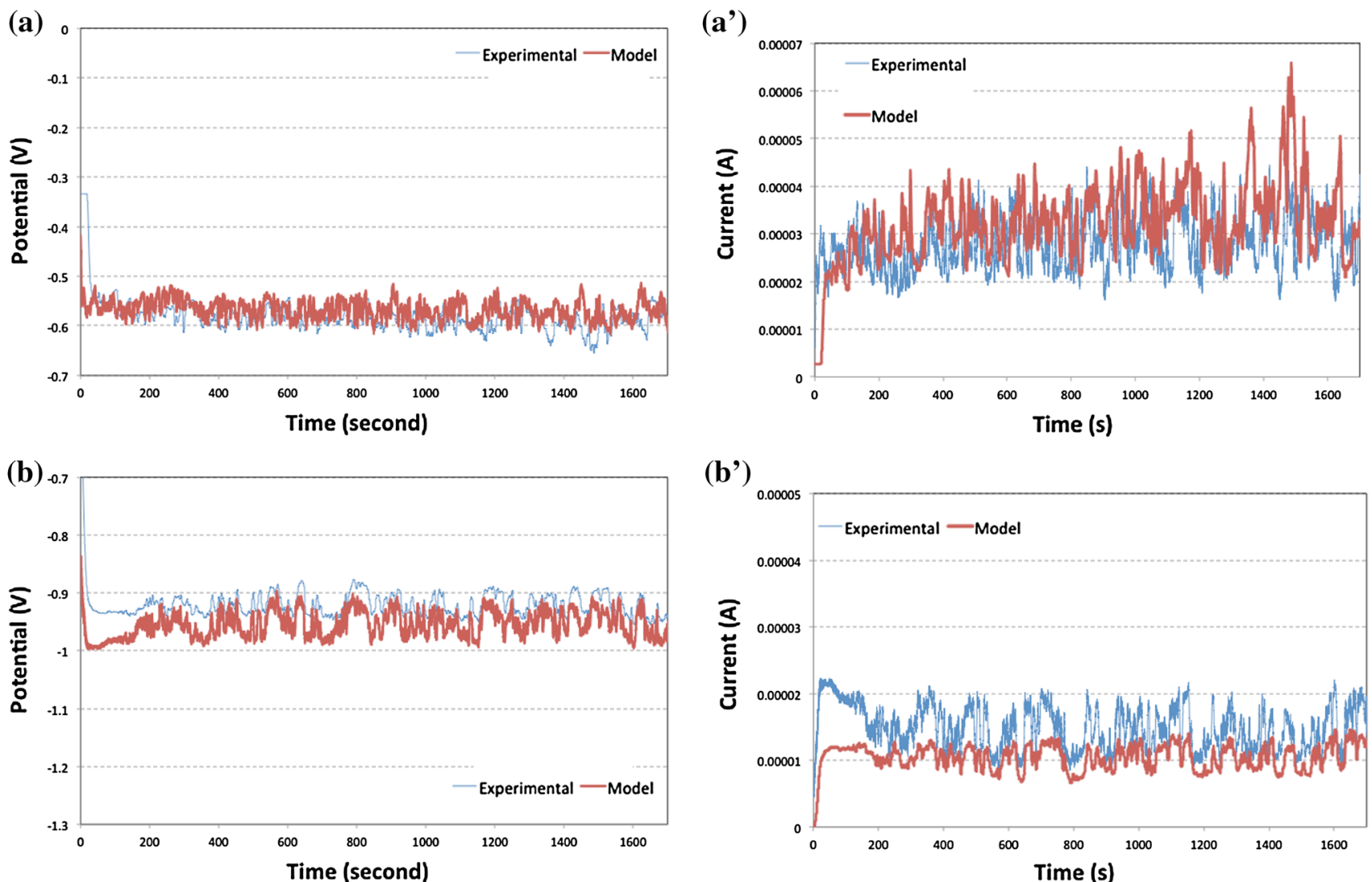

(c)

(b’)
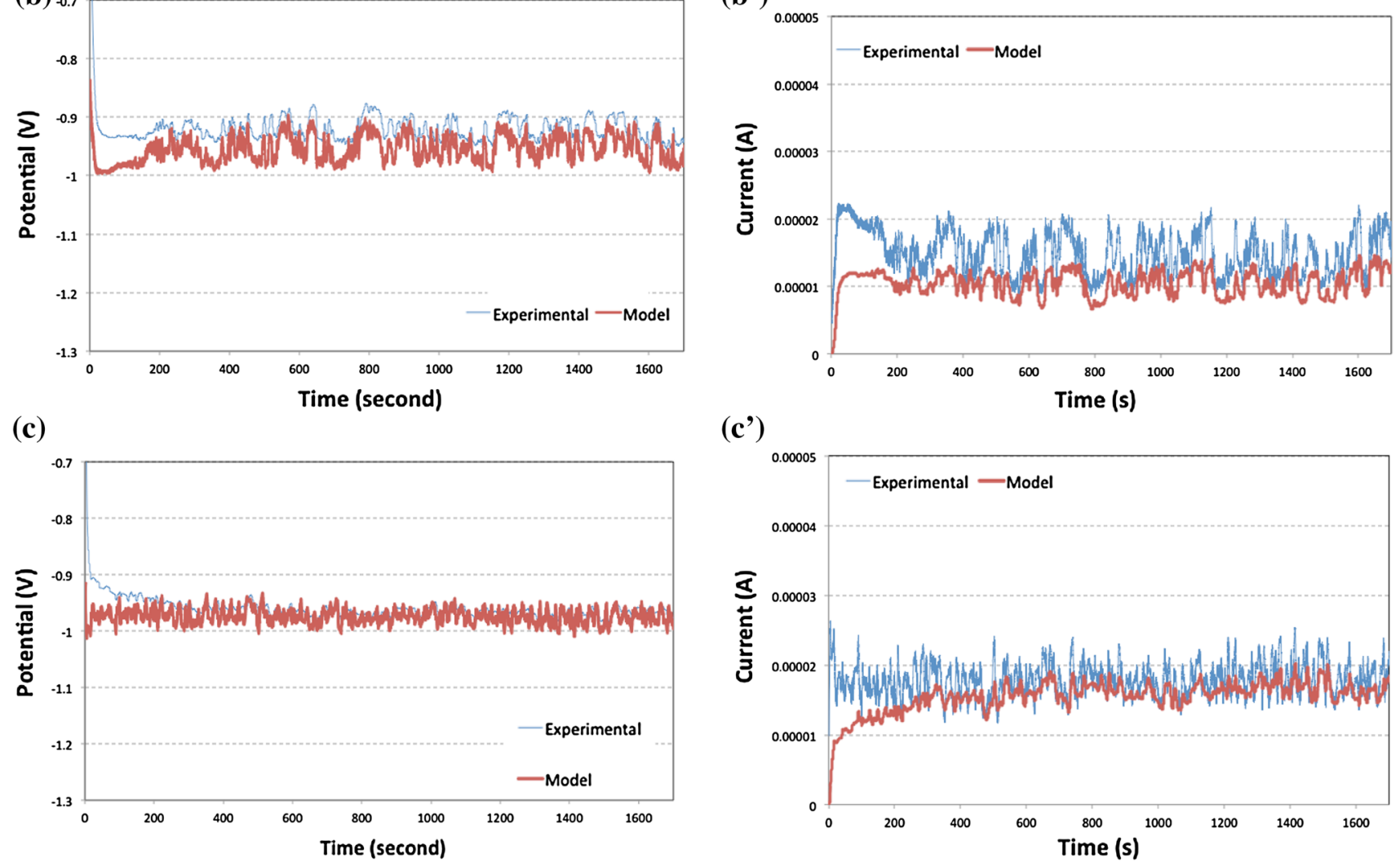

Fig. 8 Potential and current evolution with time of the Ti6Al4V rubbed against $\mathbf{a}-\mathbf{a}^{\prime} \mathrm{Al}_{2} \mathrm{O}_{3}$ ball at $540 \mathrm{MPa}, \mathbf{b}-\mathbf{b}^{\prime} \mathrm{SiC}$ pin at $830 \mathrm{MPa}$ and $\mathbf{c}-\mathbf{c}^{\prime} \mathrm{SiC}$ pin at $1,410 \mathrm{MPa}$ in artificial saliva at $37{ }^{\circ} \mathrm{C}$. The blue

against the alumina ball. In addition, a deviation from the Archard wear equation in the depassivated area was also found. When using a $\mathrm{SiC}$ pin as counterpart material and increasing the initial contact pressure to 830 and 1,410 $\mathrm{MPa}$, the current evolution and the depassivated area of contact changed. At 1,410 MPa, the depassivated area of contact followed well the Archard wear prediction as expected from a material experiencing large plastic deformation (Fig. 5c). In the other two tribocorrosion conditions, the initial contact pressure was below the yield

(c')

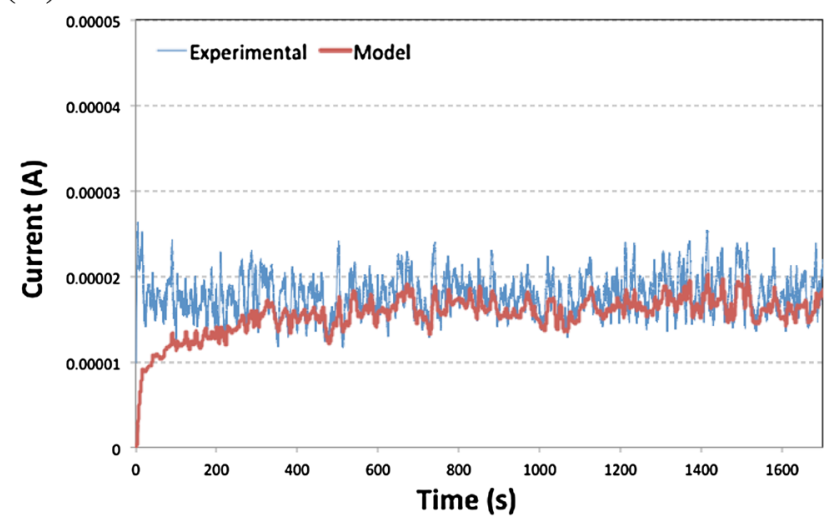

curve corresponds to the experimental data, while the red one is the simulated response according to Eqs. 3 and 4 (Color figure online)

strength of the alloy (880 MPa), and therefore, a deviation from the Archard prediction was found, which was clearly observed for the lowest initial contact pressure of $540 \mathrm{MPa}$ (Fig. 9a).

When the initial contact pressure of the tribocorrosion test was well below the yield strength of the material, wear debris was observed on the wear track after testing (Fig. 4a). This wear debris formation and its oxidation in the electrolyte contributed to an increase in the anodic current measured (Fig. 4a). In this case, the wear 
Fig. 9 Evolution of the depassivated $\left(A_{\mathrm{a}}\right)$ and Hertzian $\left(A_{\text {contact }}\right)$ areas versus time from the potential and current values measured by ZRA.

Superimposed the wear track area $\left(A_{\mathrm{wt}}\right)$ obtained by the Archard wear law and the geometry of the counterpart
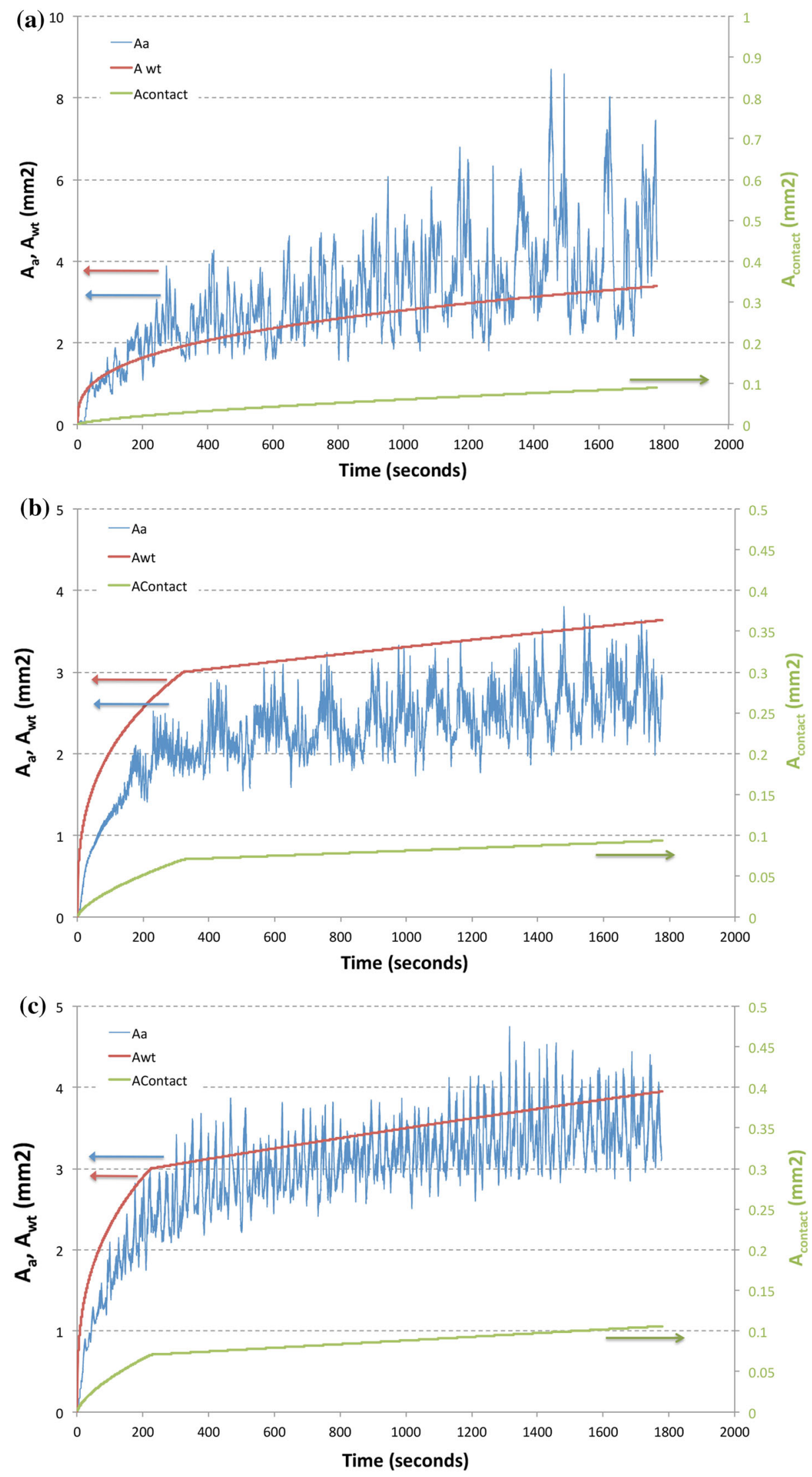

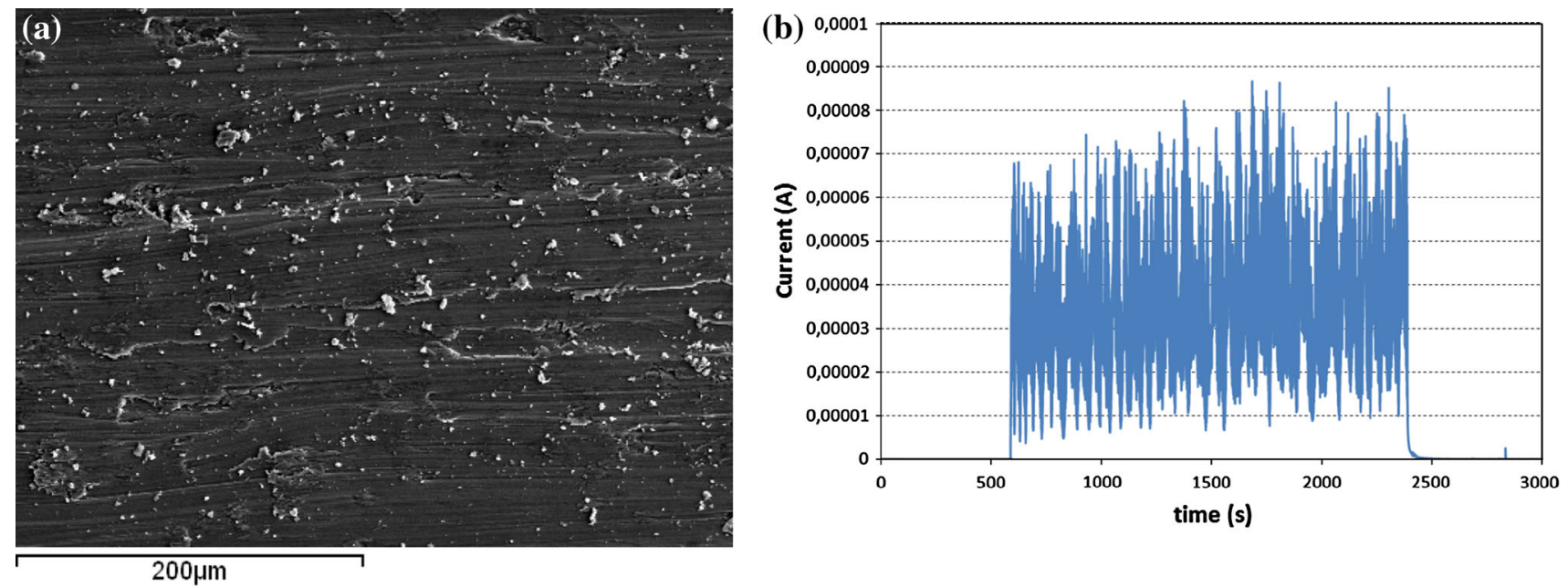

Fig. 10 a SEM image of the center of the wear track after tribocorrosion testing of a Ti6Al4V obtained by powder metallurgy in artificial saliva at OCP against alumina ball at $3 \mathrm{~N}$ normal load $(540 \mathrm{MPa})$ and $\mathbf{b}$ current evolution with time measured by ZRA

mechanism is mainly governed by the presence of the third body, which could be detected by the ZRA technique. Indeed, an identical test performed on a Ti6Al4V alloy obtained by powder metallurgy showed a larger amount of debris formed after testing; in this case, the current during rubbing was the largest of all (Fig. 10).

\section{Conclusions}

In this work, the tribocorrosion mechanisms at OCP of a Ti6Al4V biomedical alloy in AS have been investigated by means of ZRA coupled to a triboelectrochemical cell. Different initial mechanical conditions have been tested, e.g. below, above and at the yield strength of the alloy. The following conclusions can be drawn:

- The ZRA technique for tribocorrosion has been used for studying the triboelectrochemical behaviour of a Tibased biomedical alloy in AS at OCP by obtaining experimental values for the anodic current (wear accelerated corrosion during rubbing at different initial mechanical conditions).

- The experimental measurement of the anodic current and the galvanic potential of the wear track (anode) and the passive material (cathode) in a tribocorrosion test allowed for an accurate simulation of the current and potential during rubbing using the galvanic coupling model for tribocorrosion based on the kinetics of the cathodic reaction.

- The highest anodic current was obtained when the initial contact pressure was well below the yield strength of the alloy. This corresponded to a deviation of the wear behaviour from the Archard law caused by the presence of third bodies, as observed in the scanning electron microscopy analysis.

- The ZRA technique for tribocorrosion and the galvanic model allows predicting the real depassivated area and therefore, the deviation of the wear mechanisms from Archard wear law at OCP.

Acknowledgments The authors would like to thank the financial support from NTNU (Project Number 69450741) for performing the experiments of this work and Universitat Politècnica de Valencia VLC/Campus (PMIA-2013) for the mobility Grant.

\section{References}

1. Martin É, Azzi M, Salishchev GA, Szpunar J (2010) Influence of microstructure and texture on the corrosion and tribocorrosion behaviour of Ti-6Al-4V. Tribol Int 43:918-924

2. Nosonovsky M, Bhushan B (2010) Green tribology: principles, research areas and challenges. Philos Trans $\mathrm{R}$ Soc A 368:4677-4694

3. Geetha M, Singh AK, Asokamani R, Gogia AK (2009) Ti based biomaterials, the ultimate choice for orthopaedic implants-a review. Prog Mater Sci 54:397-425

4. Niinomi M, Kuroda D, Fukunaga K, Morinaga M, Kato Y, Yashiro $T$ et al (1999) Corrosion wear fracture of new $\beta$ type biomedical titanium alloys. Mater Sci Eng A 263:193-199

5. Kuroda D, Niinomi M, Morinaga M, Kato Y, Yashiro T (1998) Design and mechanical properties of new $\beta$ type titanium alloys for implant materials. Mater Sci Eng A 243:244-249

6. Eisenbarth E, Velten D, Müller M, Thull R, Breme J (2004) Biocompatibility of $\beta$-stabilizing elements of titanium alloys. Biomaterials 25:5705-5713

7. More NS, Diomidis N, Paul SN, Roy M, Mischler S (2011) Tribocorrosion behaviour of $\beta$ titanium alloys in physiological solutions containing synovial components. Mater Sci Eng C $31: 400-408$

8. Milošev I, Metikoš-Huković M, Strehblow H-H (2000) Passive film on orthopaedic TiAlV alloy formed in physiological solution 
investigated by X-ray photoelectron spectroscopy. Biomaterials 21:2103-2113

9. Komotori J, Hisamori N, Ohmori Y (2007) The corrosion/wear mechanisms of Ti-6Al-4V alloy for different scratching rates. Wear 263:412-418

10. Dimah MK, Devesa Albeza F, Amigó Borrás V, Igual Muñoz A (2012) Study of the biotribocorrosion behaviour of titanium biomedical alloys in simulated body fluids by electrochemical techniques. Wear 294-295:409-418

11. Licausi MP, Igual Muñoz A, Amigó Borrás V (2013) Tribocorrosion mechanisms of Ti6Al4V biomedical alloys in artificial saliva with different pHs. J Phys D 46:404003

12. Runa MJ, Mathew MT, Rocha LA (2013) Tribocorrosion response of the Ti6Al4V alloys commonly used in femoral stems. Tribol Int 68:85-93

13. Munoz AI, Espallargas N (2011) Tribocorrosion mechanisms in sliding contacts. In: Landolt D, Mischler S (eds) Tribocorrosion of passive metals and coatings. Woodhead Publishing, Lausanne

14. Mischler S (2008) Triboelectrochemical techniques and interpretation methods in tribocorrosion: a comparative evaluation. Tribol Int 41:573-583
15. Espallargas N, Johnsen R, Torres C, Muñoz AI (2013) A new experimental technique for quantifying the galvanic coupling effects on stainless steel during tribocorrosion under equilibrium conditions. Wear 307:190-197

16. Vieira AC, Rocha LA, Papageorgiou N, Mischler S (2012) Mechanical and electrochemical deterioration mechanisms in the tribocorrosion of $\mathrm{Al}$ alloys in $\mathrm{NaCl}$ and in $\mathrm{NaNO}_{3}$ solutions. Corros Sci 54:26-35

17. Papageorgiou N, Mischler S (2012) Electrochemical simulation of the current and potential response in sliding tribocorrosion. Tribol Lett 48(3):271-283

18. Papageorgiou N, von Bonin A, Espallargas N (2014) Tribocorrosion mechanisms of NiCrMo-625 alloy: an electrochemical modeling approach. Tribol Int 73:177-186

19. Dearnley PA, Dahm KL, Çimenoglu H (2004) The corrosionwear behaviour of thermally oxidised CP-Ti and Ti-6Al-4V. Wear 256:469-479 